\title{
Bariatric surgery in infertile women with morbid obesity: definitive solution?
}

José Maria Soares Júnior ${ }^{1}$ Alexandre Lobe/ ${ }^{1}$ Dani Ejzenberg' Paulo C. Serafini ${ }^{1}$ Edmund C Baracat ${ }^{1}$

1. Discipline of Gynaecology, Department of Obstetrics and Gynaecology, Hospital das Clínicas, Medical School, University of São Paulo, Brasil

Obesity is a global public health problem affecting over 650 million people during all stages of life, especially in the reproductive period'. In Brazil, this condition has increased dramatically: in 2006, it affected $11.8 \%$ of the population, rising to $18.9 \%$ in 2016. The numbers appear to be even worse during reproductive age: in 2013, obesity affected $20.8 \%$ of Brazilians over 18 years of age, the percentage being higher among women (24.4\%) when compared to men $(16.8 \%)^{2}$.

Clinical comorbidities of obesity, such as systemic arterial hypertension and diabetes mellitus, have an impact on the health and quality of life of this population. However, the effect on male and female fertility is another major concern ${ }^{3,4}$. There are several mechanisms associated with this subfertility, such as chronic anovulation, insulin resistance, reduction of oocyte quality and reduction of embryo implantation rate ${ }^{5,6}$. Obesity is also associated with worse obstetric and perinatal outcomes, such as high risk for preeclampsia, gestational diabetes, macrosomia, and foetal distress ${ }^{7}$.

In men, obesity can affect spermatogenesis by in- creasing testicular temperature and also by elevated serum oestrogen levels, due to the greater peripheral conversion of androgens in adipose tissue, which consequently determines inadequate feedback in the hypothalamic-pituitary-gonadal axis, altering the testicular function ${ }^{8}$. Some researchers have shown reduced concentration and sperm motility in obese patients ${ }^{9}$.

Obese female patients are often advised to lose weight before becoming pregnant, but evidence in literature is conflicting when assessing the actual effect of lifestyle changes on the couple's reproductive outcomes. There are several protocols with nutritional guidance and physical activity to reduce preconception weight with an increase in the spontaneous ovulation rate, but without significant repercussions on the number of pregnancies and, especially, on the number of live births ${ }^{10}$. In this sense, Best et al. ${ }^{11}$ systematically reviewed the impact of lifestyle changes, including adequate nutritional guidance and physical activity, on fertility. Despite considering randomized clinical trials, they concluded that it may increase the chance of pregnancy, but did not show an increase in 
the live birth rate. Another problem is the difficult adherence to the lifestyle change protocols by the patients, especially those with morbid obesity ${ }^{12}$.

Bariatric surgery may be an alternative for morbidly obese women or those with comorbidities who were unsuccessful at attempts to lose weight with behavioural measures and lifestyle changes. This surgical technique aims at reducing the capacity of food intake and/or absorption. Data from literature show a sustainable weight loss over a shorter period of time, and reduction of morbidity associated with obesity $^{13}$. It is an option for morbidly obese women with infertility who have failed with other therapies. In a survey with over 15,000 women who underwent bariatric surgery in the United Kingdom, 53\% were between 18 and 45 years old ${ }^{14}$.

Bariatric surgery restores the regular menstrual cycle, correcting ovulatory dysfunctions and adjusting the length of the follicular phase (often long in obese patients). In addition, it improves women's self-esteem, having a positive impact on the sexual function ${ }^{12-17}$. However, there are still few studies that have evaluated reproductive outcomes in patients who underwent bariatric surgery. Milone et al. ${ }^{18}$ concluded that $58 \%$ of women with infertility and submitted to bariatric surgery became pregnant spontaneously, after a systematic review of the literature. This result should be interpreted with caution, since the included studies showed a large variation $(22 \%$ to $92 \%$ of spontaneous gestation) and the evidence quality is still low in many studies ${ }^{18,19}$.

Weight reduction after bariatric surgery leads to less need for drugs during assisted reproduction techniques. Tsur et al. ${ }^{20}$ found that there was need for lower amounts of gonadotrophins for ovarian stimulation as the body mass index was lower before and after bariatric surgery. Other researchers also found a similar finding and obtained a higher number of oocytes and high quality embryos for transfer $^{21}$. However, other studies have not shown such significant results 22 .

In a study of 596 pregnancies of women who underwent bariatric surgery and data compared to 2,356 pregnancies in a paired cohort comprised of obese, non-operated women, there was a higher risk of newborns small for its gestational age $(\mathrm{OR}=2.20 ; 95 \% \mathrm{CI}$, 1.64-2.95, $\mathrm{P}<.001$ ) and higher risk of prematurity between 32 and 36 weeks and 6 days $(\mathrm{OR}=1.30,95 \% \mathrm{CI}$, 1.05-1.60) in the women with bariatric surgery. On the other hand, these patients had a lower risk of gestational diabetes $(\mathrm{OR}=0.25,95 \% \mathrm{CI}, 0.13-0.47, \mathrm{P}<0.001)$ and foetal macrosomia (OR $=0.33,95 \% \mathrm{CI}, 0.24-0.44$, $\mathrm{P}<.001)$. Therefore, there are negative and positive consequences that should be discussed with patients in the decision for bariatric surgery.

Some considerations should be made when evaluating the impact of bariatric surgery on fertility. First, it must be recognized that there are several techniques and the repercussion of each of them on the reproductive outcomes can also have its nuances and be different. We do not yet know what the preferred technique would be in patients during the reproductive age. In addition, there is uncertainty about the optimal time interval after surgery to attempt to conceive ${ }^{24,25}$. However, some guidelines suggest the minimum interval of 12 months, and others, 24 months. However, the waiting time for women over 35 years old and with low ovarian reserve raises concerns about the feasibility of pregnancy ${ }^{17-26}$.

Bariatric surgery may be an alternative for infertile women with morbid obesity but there is still the need for studies to know the ideal type of surgery as well as the time span required to minimize the complications of such procedure on gestation.

\section{REFERENCES}

1. World Health Organization. Obesity and overweight: fact sheet. February, 2018 [Acessed 2018 Jan 5]. Available from: http://www.who.int/mediacentre/factsheets/fs311/en/.

2. Ministério da Saúde. Vigitel Brasil 2016: hábitos dos brasileiros impactam no crescimento da obesidade e aumenta prevalência de diabetes e hipertensão. [Acessed 2018 Jan 5]. Brasília: Ministério da Saúde; 2016. Available from: http://portalarquivos.saude.gov.br/images/pdf/2017/abril/17/Vigitel_17-4-17-final.pdf.

3. Gesink Law DC, Maclehose RF, Longnecker MP. Obesity and time to pregnancy. Hum Reprod. 2007;22(2):414-20.

4. Gaskins AJ, Rich-Edwards JW, Missmer SA, Rosner B, Chavarro JE. Association of fecundity with changes in adult female weight. Obstet Gynecol. 2015;126(4):850-8.

5. Zain MM, Norman RJ. Impact of obesity on female fertility and fertility treatment. Womens Health (Lond). 2008;4(2):183-94.

6. Klenov VE, Jungheim ES. Obesity and reproductive function: a review of the evidence. Curr Opin Obstet Gynecol. 2014;26(6):455-60.

7. Lesko I, Peaceman A. Pregnancy outcomes in women after bariatric surgery compared with obese and morbidly obese controls. Obstet Gynecol. 2012;119(3):547-54

8. Sallmén M, Sandler DP, Hoppin JA, Blair A, Baird DD. Reduced fertility among overweight and obese men. Epidemiology. 2006;17(5):520-3.

9. Sermondade N, Faure C, Fezeu L, Shayeb AG, Bonde JP, Jensen TK, et al. $\mathrm{BMI}$ in relation to sperm count: an updated systematic review and collaborative meta-analysis. Hum Reprod Update. 2013;19(3):221-31. 
10. Sim KA, Partridge SR, Sainsbury A. Does weight loss in overweight or obese women improve fertility treatment outcomes? A systematic review. Obes Rev. 2014;15(10):839-50.

11. Best $D$, Avenell $A$, Bhattacharya $S$. How effective are weight-loss interventions for improving fertility in women and men who are overweight or obese? A systematic review and meta-analysis of the evidence. Hum Reprod Update. 2017;23(6):681-705.

12. Legro RS. Effects of obesity treatment on female reproduction: results do not match expectations. Fertil Steril. 2017;107(4):860-7.

13. Buchwald $H$, Avidor $Y$, Braunwald E, Jensen MD, Pories W, Fahrbach $K$, et al. Bariatric surgery: a systematic review and meta-analysis. JAMA. 2004;292(14):1724-37.

14. Edison E, Whyte M, van Vlymen J, Jones S, Gatenby P, Lusignan S, et al. Bariatric surgery in obese women of reproductive age improves conditions that underlie fertility and pregnancy outcomes: retrospective cohort study of UK National Bariatric Surgery Registry (NBSR). Obes Surg. 2016;26(12):2837-42

15. Reis LO, Zani EL, Saad RD, Chaim EA, Oliveira LC, Fregonesi A. Bariatric surgery does not interfere with sperm quality: a preliminary long-term study. Reprod Sci. 2012;19(10):1057-62.

16. Sermondade N, Massin N, Boitrelle F, Pfeffer J, Eustache F, Sifer C, et al. Sperm parameters and male fertility after bariatric surgery: three case series. Reprod Biomed Online. 2012;24(2):206-10

17. Practice Committee of the American Society for Reproductive Medicine. Obesity and reproduction: a committee opinion. Fertil Steril. 2015;104(5):1116-26.

18. Milone M, De Placido G, Musella M, Sosa Fernandez LM, Sosa Fernandez LV, Campana G, et al. Incidence of successful pregnancy after weight loss interventions in infertile women: a systematic review and meta-analysis of the literature. Obes Surg. 2016;26(2):443-51.

19. Doblado MA, Lewkowksi BM, Odem RR, Jungheim ES. In vitro fertilization after bariatric surgery. Fertil Steril. 2010;94(7):2812-4.

20. Tsur A, Orvieto R, Haas J, Kedem A, Machtinger R. Does bariatric surgery improve ovarian stimulation characteristics, oocyte yield, or embryo quality? J Ovarian Res. 2014;7:116

21. Milone M, Sosa Fernandez LM, Sosa Fernandez LV, Manigrasso M, Elmore U, De Palma GD, et al. Does bariatric surgery improve assisted reproductive technology outcomes in obese infertile women? Obes Surg. 2017;27(8):2106-12.

22. Christofolini I, Bianco B, Santos G, Adami F, Christofolini D, Barbosa CP. Bariatric surgery influences the number and quality of oocytes in patients submitted to assisted reproduction techniques. Obesity (Silver Spring). 2014;22(3):939-42.

23. Johansson K, Cnattingius S, Näslund I, Roos N, Trolle Lagerros Y, Granath $F$, et al. Outcomes of pregnancy after bariatric surgery. N Engl J Med. 2015;372(9):814-24

24. Parent B, Martopullo I, Weiss NS, Khandelwal S, Fay EE, Rowhani-Rahbar A. Bariatric surgery in women of childbearing age, timing between an operation and birth, and associated perinatal complications. JAMA Surg. 2017;152(2):1-8

25. Roos N, Neovius M, Cnattingius S, Trolle Lagerros Y, Sääf M, Granath F, et al. Perinatal outcomes after bariatric surgery: nationwide population based matched cohort study. BMJ. 2013;347:f6460.

26. Nomura RM, Dias MC, Igai AM, Paiva LV, Zugaib M. Anemia during pregnancy after silastic ring Roux-en-Y gastric bypass: influence of time to conception. Obes Surg. 2011;21(4):479-84. 